\title{
Evaluation of Trihalomethane Formation Potential Due to Anthropogenic Sources in the Ground Water of Kanpur
}

\author{
NIDHI DIXIT MISHRA, S. C. DIXIT* and H. C. SRIVASTAVA \\ Department of Chemistry, \\ D.B.S. Post-Graduate College, Kanpur-208006, India \\ satishdixit1@gmail.com
}

Received 6 September 2011; Accepted 25 October 2011

\begin{abstract}
The ground water of Jajmau(which is the hub of tanneries), Kanpur has been evaluated for trihalomethane formation potential in January and May, 2009.Bromide is absent. Chloroform is the only THM species identified in all the ground water samples. The levels of chloroform are found below the regulated WHO guideline value of $300 \mu \mathrm{gL}^{-1}$. THM formation rate is very fast in first $24 \mathrm{~h}$. as compared to that of the exceeding reaction time ( $>24 \mathrm{~h})$. High TOC content is found in both the winter and summer seasons. Values of THMFP increase as the chlorine doses from $14 \mathrm{mg} / \mathrm{L}$ to $17 \mathrm{mg} / \mathrm{L}$ increased in both the seasons.
\end{abstract}

Keywords: Trihalomethane formation potential, Ground Water, WHO, Gas Chromatograph, Chlorine, TOC.

\section{Introduction}

It has been said that water will probably be the next resource over which wars will be fought. This shows the importance of the potable water, which is about $0.009 \%$ of the whole water in planet. Increased global population and the industrial revolution has increased the water scarcity. Industrialization has polluted the water bodies meant for drinking and other purposes. Consequently, providing enough access to safe drinking water has become one of the main challenges to any government. To bridge the gap between the demand and the availability of potable water, the emphasis is on rainwater harvesting, ground water investigations etc. amongst others.

Chlorine disinfection processes and other oxidation processes to inactivate harmful microorganisms are questioned by the potentially toxic by-products formed during disinfection. Chloroform, a trihalomethane produced during chlorination, was shown to be a carcinogen for mice and rats ${ }^{1}$. THMs are the most commonly occurring and toxic DBPs found in chlorinated waters and were first reported by Bellar ${ }^{2}$ and Rook ${ }^{3}$. In India, the occurrence of THMs in chlorinated waters has been reported for the first time by Satyanarayana ${ }^{4}$ and 
Thacker ${ }^{5,6}$. Epidemiology studies have suggested that bladder, rectal and colon cancer are potentially associated with the drinking of chlorinated water ${ }^{7}$. THMs may cause colon cancer in humans and bromodichloromethane causes a high incidence of colon cancer in rats $^{8}$. Reports have shown that bromodichloromethane has a stronger association with stillbirths and neural tube defects than any other THM species ${ }^{9}$. Guariglla and co-workers ${ }^{10}$ examined the effects of THMs on behaviour in mice and found that mice evidenced few vocalizations, anxiety, repetitive behaviours and social deficits. Males not females, consistently displayed these autistic-like behaviours. Chen et al. ${ }^{11}$ conducted one year long monitoring to assay the concentrations of THMs, HAAs and their formation potential along the conventional process in a water treatment plant in China and found that concentration of DBPs and their formation potential varied with the seasons. World Health Organization $(\mathrm{WHO})^{12}$ has regulated the health related guideline values $(\mathrm{GV})$ for THMs in drinking water.

Table 1. WHO guideline values for drinking water quality- $4^{\text {th }}$ Edition $(2011)^{12}$.

\begin{tabular}{ccc}
\hline $\begin{array}{c}\text { Disinfection } \\
\text { by-products }\end{array}$ & $\begin{array}{c}\text { Guideline } \\
\text { Values, } \mu \mathrm{g} / \mathrm{L}\end{array}$ & Remarks \\
\hline Trihalomethanes & ---- & $\begin{array}{c}\text { The sum of the ratio of the concentration } \\
\text { of each to its respective guideline value } \\
\text { should not exceed 1 }\end{array}$ \\
$\begin{array}{c}\text { Bromoform } \\
\text { Chlorodibromomethane }\end{array}$ & 100 & \\
Bromodichloromethane & 60 & \\
Chloroform & 300 & \\
\hline
\end{tabular}

THM formation potential (THMFP) is influenced by the amount and characteristics of dissolved organic matter (DOM) present in the sample. THMFP was found to be directly related with dissolved organic carbon (DOC).The following paper reports the quality of ground water monitored in January and May,2009 for THMFP as chloroform, bromodichloromethane, chlorodibromomethane and bromoform in Jajmau area of Kanpur City. Jajmau is the hub of tanneries which prompted us to carry out the study of ground water quality in this area.

\section{Experimental}

All chemicals used were of the analytical reagent grade unless specified otherwise. High purity gas was used for various experimental purposes. De-ionized water obtained from a Milli-Q system (Millipore, USA) was used for all experimental purposes.

Borosilicate glass (ASTM type-I, Wheaton Science, Millville, NJ, USA) vials of $40 \mathrm{~mL}$ equipped with screw caps having Teflon faced re-sealable septa were used. The 1L capacity reagent bottles to preserve the chlorinated samples and $300 \mathrm{~mL}$ reagent bottles to quench the samples were also made of borosilicate glass. Micro syringes (Hamilton, USA) of $10 \mu \mathrm{L}$, $50 \mu \mathrm{L}, 100 \mu \mathrm{L}, 500 \mu \mathrm{L}$ and $1000 \mu \mathrm{L}$ were used during the experiments. The washing protocol for the vials involved rinsing with tap water to remove sample or solvent residues as the first step. Then the vials were kept overnight in a chromic acid bath. Next, the vials were washed thoroughly with phosphate free laboratory detergent and rinsed thoroughly with tap water and later rinsed with deionized (Milli-Q) water. After washing, the glassware were kept in an oven at $200{ }^{\circ} \mathrm{C}$ for drying, and later stored in a vacuum desiccator before final use. Re- usable septa were washed with phosphate free laboratory detergent and then 
thoroughly rinsed with tap water. Then they were rinsed with deionized water and kept in an oven at $60^{\circ} \mathrm{C}$ for 2-3 h. Septa were stored in a vacuum desiccator before use in experiments. Clear $2 \mathrm{~mL}$ gas chromatograph (GC) auto sampler vials with $11 \mathrm{~mm}$ aluminum seals and PTFE rubber lined septa (Wheaton Science, USA) were used for sample storage for gas chromatographic (GC) analysis. These vials were used only once before disposal. All other glassware used in this study were also made of borosilicate glass, and purchased from Borosil, India. Before use, glassware were acid washed, followed by rinsing with tap water, distilled water and then dried in an oven at $180^{\circ} \mathrm{C}$.

For THM formation potential analysis, Jajmau was selected because it is the hub of tanneries. Groundwater samples were collected in January and May, 2009. All the experiments were completed with utmost precaution and Standard Methods (APHA, 2005) ${ }^{13}$ were referred to conduct experiments unless otherwise specified. In a typical experiment, ground water samples were chlorinated with 2 different chlorine doses. The free chlorine residuals (FCR) and combined chlorine residuals (CCR) were measured for each sample and at each chlorine dose applied. THMs (4 compounds) concentrations were measured at 3 different contact times after chlorination. The formation potentials (FP) for the above compounds were measured 7 days after chlorination. UV absorbance@254 nm, bromide concentration and total organic carbon (TOC) were also measured for all water samples.

Pure compounds (THMs and the internal standard) were diluted to required concentrations using MTBE (Methyl-Tertiary-Butyl-Ether). Five point calibration curves were prepared for GC for all the 4 THMs. All the curves were linear in nature. Extraction efficiencies for all the compounds were checked prior to the actual experiments and calibration curves were redrawn if recoveries were not found in the range of $90-110 \%$. Standard calibration curves were also prepared for TOC analyzer and Ion chromatograph (IC) to analyze total organic carbon and bromide concentration of water samples.

\section{Chlorine application}

A stock solution of sodium hypochlorite $(1000 \mathrm{mg} / \mathrm{L})$ was prepared. As a preliminary exercise, ground water samples were chlorinated with different doses and the chlorine demand of the samples was determined using FAS/DPD titration method. Two dosages were finalized such that there was enough free chlorine residual after $30 \mathrm{~min}$ of chlorination. Ground water samples were taken in $1 \mathrm{~L}$ capacity reagent bottles. Hypochlorite solution was added to these bottles to achieve the required chlorine concentration. The bottle contents were mixed and stored at $20^{\circ} \mathrm{C}$. Chlorine residuals (FCR, CCR) were measured after $30 \mathrm{~min}$ of chlorination using FAS/DPD titration.

\section{Extraction of disinfection by products}

Samples were extracted in duplicate for THM determination. For a typical extraction, after specified contact time, a $50 \mathrm{~mL}$ aliquot was used. Sodium sulfite was added to the aliquot to quench the available free chlorine before extraction. EPA method 551.1 was adapted for extraction of THMs. Liquid-liquid extraction method has been used for the determination of THMs in aqueous samples. This method is also known as solvent extraction and partitioning, it is used to separate compounds based on their relative solubilities in two different immiscible liquids, usually water and an organic solvent. For the extraction of THMs, $20 \mathrm{~mL}$ quenched aliquot was taken in a $40 \mathrm{~mL}$ glass vial and $3 \mathrm{~mL}$ MTBE was added followed by $8 \mathrm{~g}$ sodium sulfate. For proper mixing, the vial was kept in a secure horizontal position for some time with the undissolved sodium sulfate distributed along the length of the vial. $1 \mathrm{~mL}$ of the upper organic layer was taken into $2 \mathrm{~mL} \mathrm{GC}$ vial and $10 \mu \mathrm{L}$ of Internal Standard (10 ppm, 1-2 dibromopropane) was added by using a $50 \mu \mathrm{L}$ syringe. All 
chromatographic analyses were performed using a Gas Chromatograph equipped with an electron capture detector (Model: 910, Buck Scientific, USA). A packed column (Resteck MS-5A $100 / 12010 \mathrm{ft} 2 \mathrm{~mm}$ ID $1 / 8^{\text {th }}$ in OD, SILCO SRI 8610C) was used. Samples were extracted from GC auto sampler vials using a micro syringe. Injection volume was $1 \mu \mathrm{L}$ in all cases. High purity (zero grade) Helium and Nitrogen were used as the carrier and make up gases respectively. Carrier and make up gas flow were about $30 \mathrm{~mL} \mathrm{~min}^{-1}$ and $60 \mathrm{~mL} \mathrm{~min}^{-1}$ respectively. The concentration of dissolved organic carbon was detected with a TOC analyzer (Model: TOC-5000A, Shimadzu, Japan). The concentration of bromide ion was measured by ion chromatograph (Model: 761 compact IC, Met Rohm, USA). UV absorbance at $254 \mathrm{~nm}\left(\mathrm{UV}_{254}\right)$ was measured with a spectrophotometer (UV-VIS, Varian,USA).

\section{Results and Discussion}

The various water quality parameters measured in each sample were : pH, TOC, $\mathrm{UV}_{254}$, alkalinity and bromide.

Table 2. Ground water quality parameters.

\begin{tabular}{ccc}
\hline & Jan.,2009 & May, 2009 \\
\hline TOC, mg/L & 18.8 & 22 \\
Alkalinity $\left(\mathrm{as} \mathrm{CaCO}_{3}\right)(\mathrm{mg} / \mathrm{L})$ & 260 & 272 \\
Bromide, $\mathrm{mg} / \mathrm{L}$ & 0 & 0 \\
$\mathrm{pH}$ & 7.7 & 7.7 \\
SUVA & 3.1 & 3.22 \\
\hline
\end{tabular}

The ground water samples were collected in January, 2009. At different chlorine dosages, the THMFP values were: $210.2(14 \mathrm{mg} / \mathrm{L}), 242.32(15 \mathrm{mg} / \mathrm{L}), 288.12(16 \mathrm{mg} / \mathrm{L})$ and $320.4(17 \mathrm{mg} / \mathrm{L}) \mu \mathrm{g} / \mathrm{L}$. Chloroform was the only THM species identified in all the samples, none of the Br-THMs were identified. All the values were below the WHO GV except the value at $17 \mathrm{mg} / \mathrm{L}$ chlorine dose. The total THMs levels were below the WHO GV of $\leq 1$ except the value at $17 \mathrm{mg} / \mathrm{L}$ chlorine dose.

The ground water samples were collected in May, 2009. At different chlorine dosages, THMFP values were: 235.34(14 $\mathrm{mg} / \mathrm{L}), 268.5(15 \mathrm{mg} / \mathrm{L}), 295.4(16 \mathrm{mg} / \mathrm{L})$ and $335.5(17 \mathrm{mg} / \mathrm{L}) \mu \mathrm{g} / \mathrm{L}$. Chloroform was the only THM species identified in all the samples .All the values were below the WHO GV except the value at $17 \mathrm{mg} / \mathrm{L}$ chlorine dose. The total THMs levels(sum of the ratio of the concentrations of each THM to its respective GV) were below the WHO GV of $\leq 1$ except the value at $17 \mathrm{mg} / \mathrm{L}$ chlorine dose.

Seasonal variations in THMFP

Seasonal variation was observed in the THMFP values in the ground water samples. The THMFP values of May(summer) were higher than the values of January,2009(winter) (Figure 1). Among individual THM species, only chloroform was found in all the seasons.

\section{Relationship between reaction time and THMFP}

The investigation of the ground water samples revealed that the THM formation rate in first $24 \mathrm{hrs}$.was very fast as compared to that of the exceeding reaction time $(>24 \mathrm{~h})$. Chloroform was the only THM species present in all the samples. Higher the reaction time led to the higher chloroform concentration which was very prominent for higher chlorine dosages. The values of THMFP showed the increasing pattern with higher chlorine dosages (Figure 2\&3). 


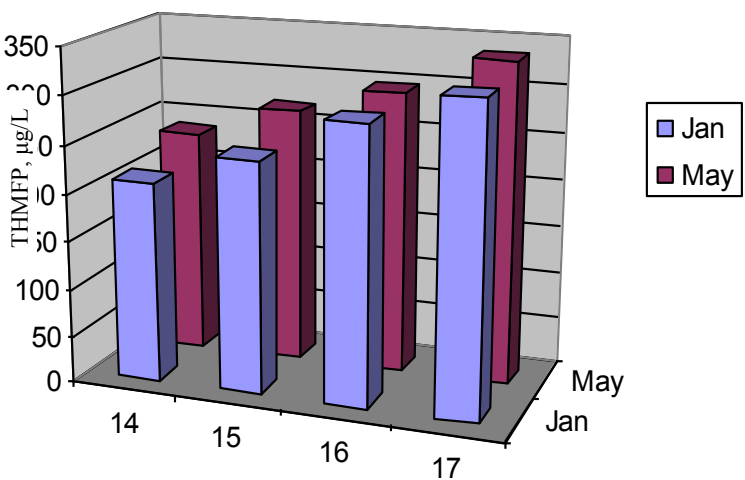

Chlorine doses, $\mathrm{mg} / \mathrm{L}$

Figure 1. Seasonal variation of THMFP for Jajmau ground water at different chlorine doses.
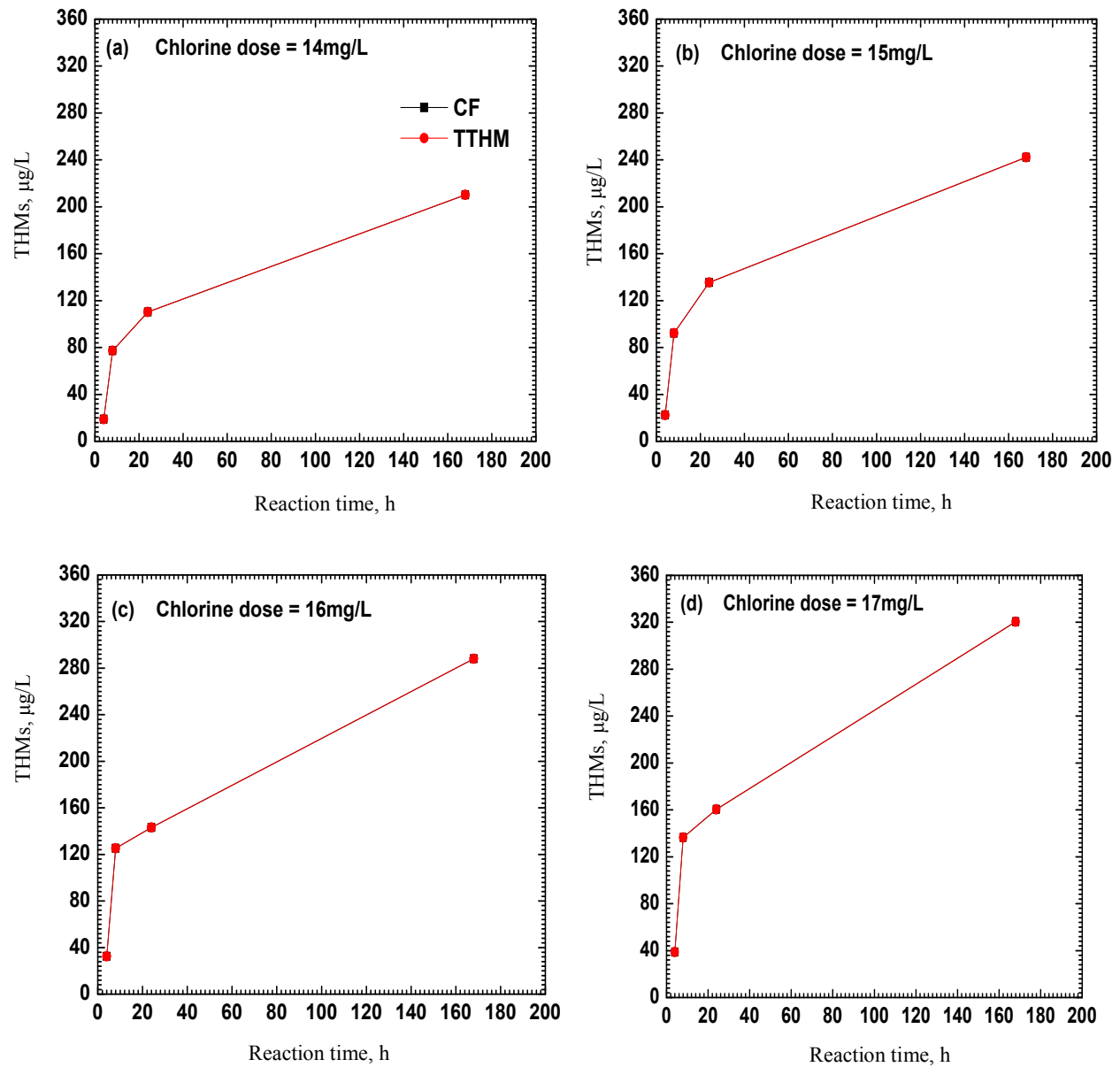

Figure 2. Effect of reaction time on THMs formation at different chlorine doses in the ground water sample collected from Jajmau in January, 2009. 

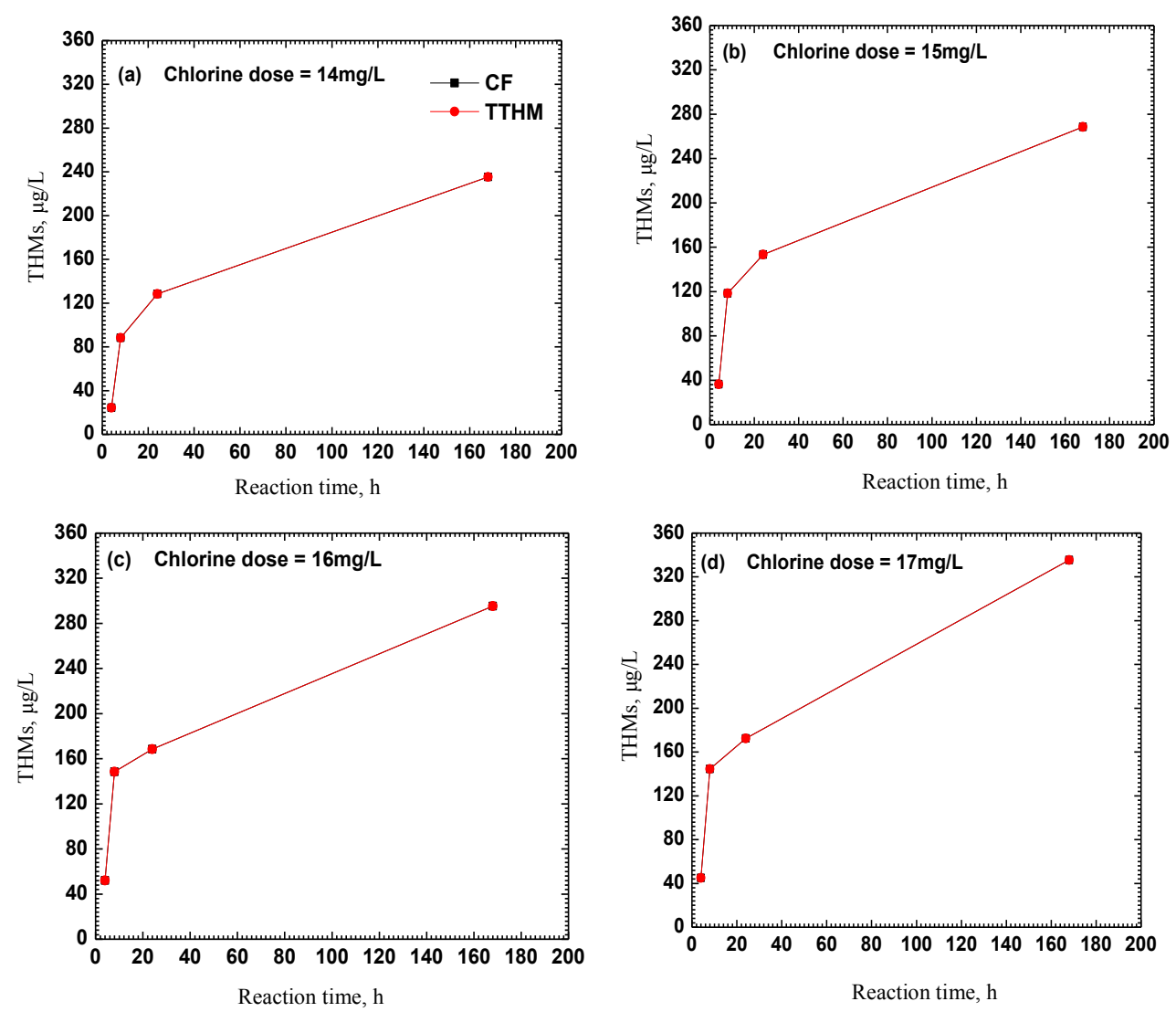

Figure 3. Effect of reaction time on THMs formation at different chlorine doses in the ground water sample collected from Jajmau in May, 2009.

Temporal variations in THMFP

The values of THMFP showed increase in May from January, 2009.

\section{Effect of Chlorine dosages on THMFP}

The values of THMFP in January and May increased as the chlorine dosages from $14 \mathrm{mg} / \mathrm{L}$ to $17 \mathrm{mg} / \mathrm{L}$ increased (Figure 1).

\section{Total organic carbon (TOC) and Its Impact on THMFP}

The samples showed high TOC content in both the seasons (winter and summer). As Jajmau is the hub of tanneries that gives rise to toxic pollutants and finally lead to dominance of TOC in the groundwater. The liquid phase toxic pollutants drained out from above industries percolate down and perturb the local groundwater quality effectively. The THMFP values were below the WHO GV except the value at $17 \mathrm{mg} / \mathrm{L}$ chlorine dose. 


\section{Conclusion}

The quality of ground water was monitored for THMFP in Jajmau, Kanpur in January and May, 2009. Bromide was absent in all the samples. Chloroform was the only THM species identified in all the ground water samples. .All the values were below the WHO GV except the value at $17 \mathrm{mg} / \mathrm{L}$ chlorine dose. The total THMs levels were below the WHO GV of $\leq 1$ except the value at $17 \mathrm{mg} / \mathrm{L}$ chlorine dose. THMFP values of summer (May) were higher than the winter (January) showing the temperature impact.THM formation rate in first $24 \mathrm{~h}$ was very fast as compared to that of the exceeding reaction time $(>24 \mathrm{~h})$. Higher the reaction time led to higher chloroform concentration which is very prominent for higher chlorine doses. The values of THMFP showed the increasing pattern with higher chlorine doses. TOC contents in both the seasons were quite high.

\section{Acknowledgment}

One of the authors NDM is sincerely acknowledging the assistance given by Dr. N.P.Thacker, a luminary at NEERI, Nagpur (India) in the form of advice and valuable guidance whenever required.

\section{References}

$1 \quad$ Clark R M, Adams J Q and Lynkins B W, J Env Eng., 1994, 120, 759-782.

2 Bellar T A, Lightenburg J J and Kroner R C, J Am Water Works Assoc., 1974, 66(12), 703-706.

3 Rook J J, J of American Water Works Assoc., 1976, 68(3), 168.

4 Satyanarayana M and Chandrasekhar, Indian J Environ Prot., 1996, 16(6), 423-426.

5 Thacker N P, Vaidya M, Sipani M, Kaur P and Rudra A, $22^{\text {nd }}$ Water Eng and Dev Center, Conference held at New Delhi, 1996, 2, 361-362.

6 Thacker N P, Kaur P and Rudra A, Environ Educ Inf., 1997, 16(4), 367-376.

7 Twerdok L E, Burton D T, Gardner H S, Shed T R and Wolfe M J, Environ Toxicol Chem., 1997, 16, 1816-1820.

8 Itoh S and Matsuoka Y, Water Res., 1996, 30, 1403-1410.

9 Chowdhury S, Champangne P and James McLellan P, Water Res., 2010, 44(7), 2349-2359.

10 Guariglla S R, Jenkins Jr E C, Chadman K K and Wen G Y, Neuro Toxicol., 2011, article in press, Available Online 29 June2011.

11 Chen C, Zhang X, Zhu L, Liu J, He W and Han H, Science Total Environment, 2008, 397(1-3), 140-147.

12. WHO Guidelines for Drinking Water Quality $-4^{\text {th }}$ Edition, World Health Organization, Geneva, 2011, 427.

13 American Public Health Association(APHA), American Water Works Association (AWWA) and Water Environment Federation(WEF): Standard Methods for the Examination of Water and Waste Water, $21^{\text {st }}$ Edition, 2005, Washington, D.C. 


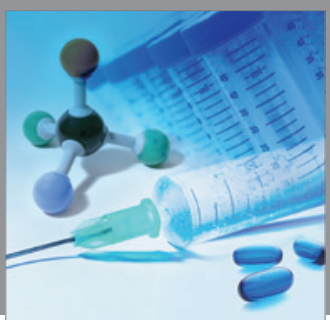

International Journal of

Medicinal Chemistry

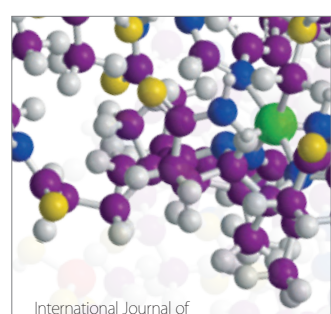

Carbohydrate Chemistry

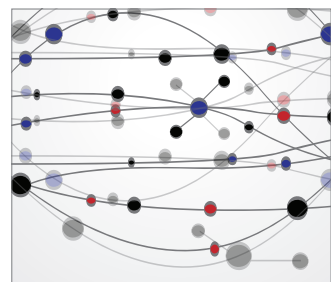

The Scientific World Journal
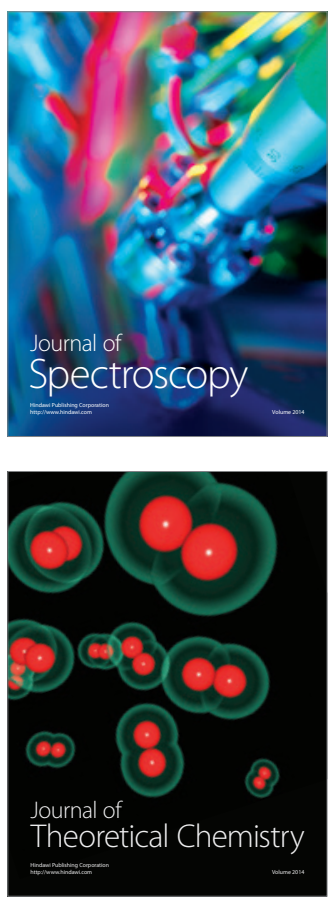
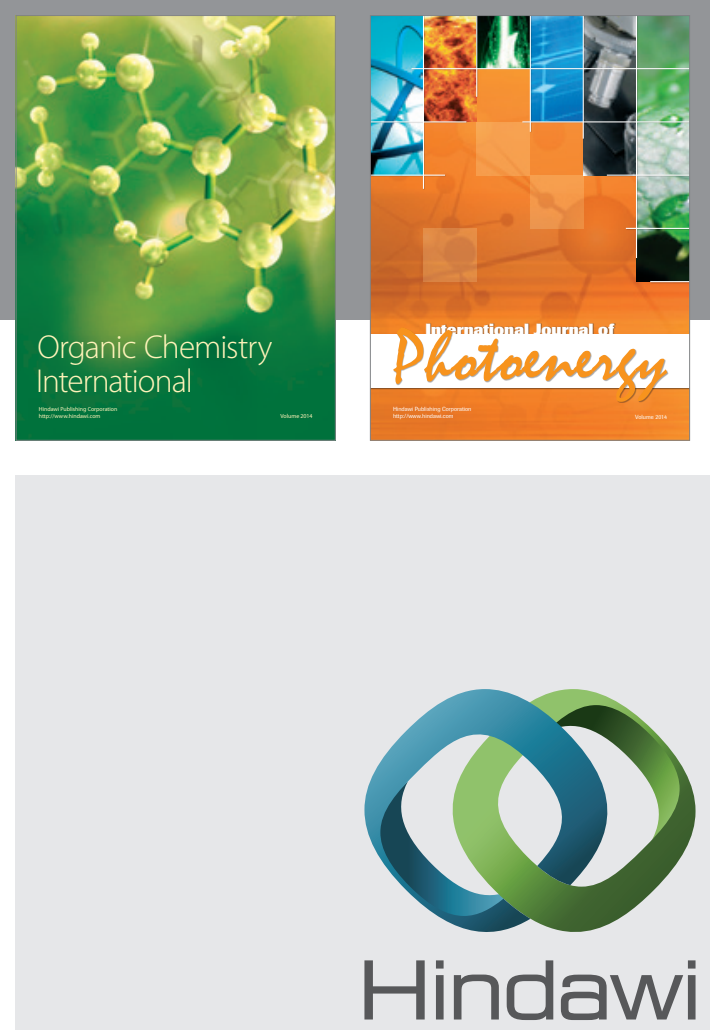

Submit your manuscripts at

http://www.hindawi.com
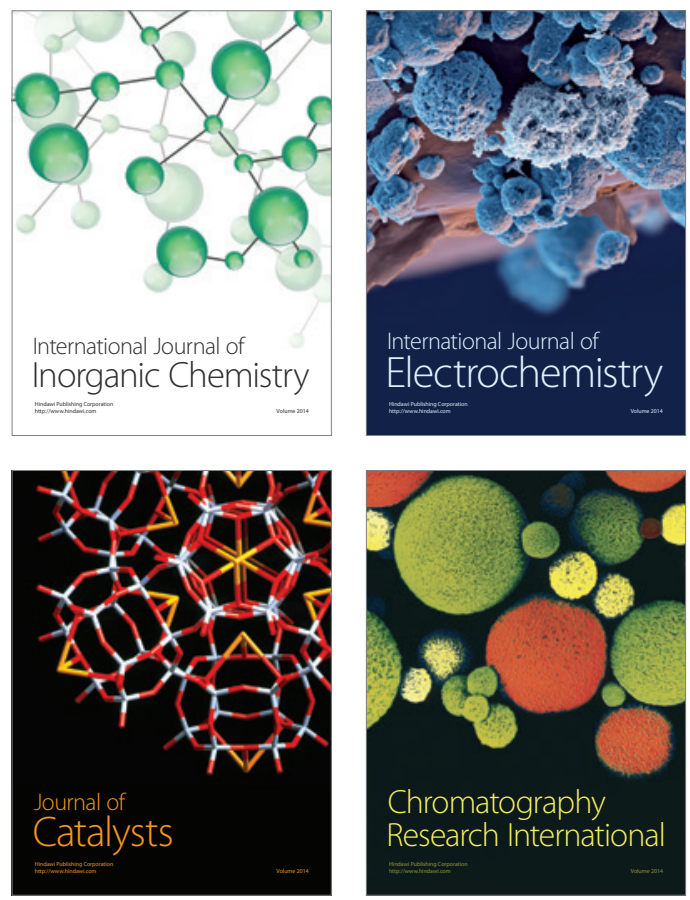
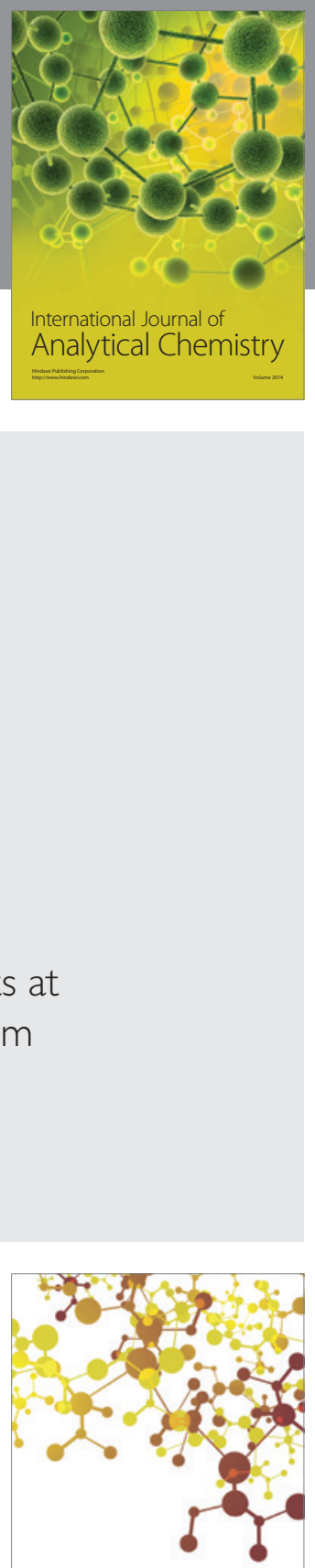

Journal of

Applied Chemistry
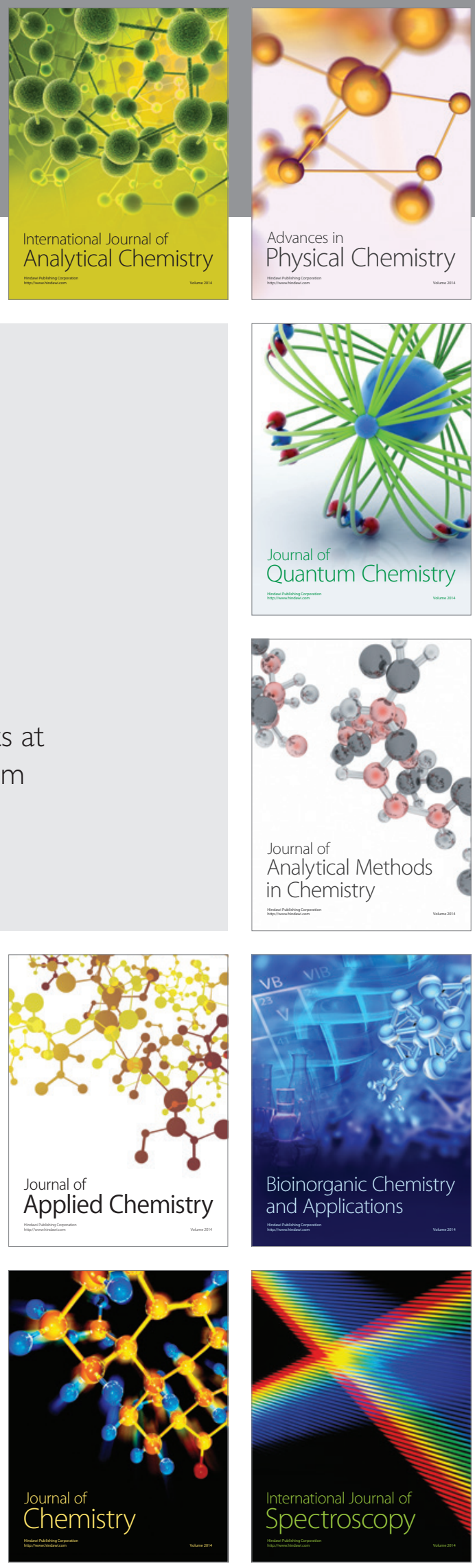